Bull. Mater. Sci., Vol. 21, No. 3, June 1998, pp. 189-193. (C) Indian Academy of Sciences.

\title{
Synthesis, characterization and application of a derivatized acid salt of tetravalent metal: $o$-chlorophenol anchored onto zirconium tungstate
}

\author{
BEENA PANDIT and UMA CHUDASAMA* \\ Department of Applied Chemistry, M.S. University of Baroda, Vadodara 390001 , India
}

MS received 2 February 1998; revised 23 April 1998

\begin{abstract}
Tetravalent metal acid (TMA) salt zirconium tungstate ( $Z W$ ) has been synthesized, followed by its derivatization using ortho chlorophenol (ZWoCP). ZWoCP has been characterized for elemental analysis, spectral analysis (FTIR) and thermal analysis (TGA). Its chemical stability has been assessed in various acidic, basic and organic media. Ion exchange capacity (IEC) has been determined and distribution behaviour towards several metal ions in different electrolyte concentrations studied and a few binary separations achieved.
\end{abstract}

Keywords. Tetravalent metal acid salts; derivatized TMA salts.

\section{Introduction}

Tetravalent metal acid salts are obtained as amorphous and crystalline materials (Clearfield and Stynes 1964). These compounds have the general formula M(IV) $\left(\mathrm{HXO}_{4}\right)_{2} \cdot \mathrm{nH}_{2} \mathrm{O}$, where $\mathrm{M}(\mathrm{IV})=\mathrm{Zr}, \mathrm{Ti}, \mathrm{Th}, \mathrm{Ce}, \mathrm{Sn}$, etc and $\mathrm{X}=\mathrm{P}, \mathrm{Mo}, \mathrm{W}, \mathrm{Sb}, \mathrm{As}$, etc. The protons of the $\mathrm{OH}$ group can be exchanged for several metal ions and thus these materials are termed as inorganic ion exchangers.

TMA salts can be derivatized by organic moieties bearing ionogenic groups such as $-\mathrm{OH},-\mathrm{COOH},-\mathrm{SO}_{3} \mathrm{H}$, etc which also act as ion exchangers. These compounds are known as inorgano-organic ion exchangers or derivatized tetravalent metal acid (DTMA) salts (Alberti et al 1978, 1980, 1982; Kornyei 1982).

Interest in DTMA salts stems from the fact that the inorganic backbone provides a stable and relatively inert anchor for the organic moiety. DTMA salts have the added advantage of both their counterparts in terms of thermal and chemical stability and ion exchange capacity. Derivatization of the inorganic ion exchangers by organic molecules depends on the nature of the inorganic matrix.

In layered materials the organic molecules are incorporated within the layers (Maya and Danis 1980; Costantino et al 1986), whereas in non layered materials the organic molecules get either anchored, sorbed on the surface or get encapsulated within the pores of the matrix. Preparation of organic derivatives of inorganic TMA salts has been studied (Alberti et al 1978, 1980, 1982; Kornyei 1982) by intercalation of polar organic

*Author for correspondence molecules such as alcohols, glycols, acetone, urea and its derivatives or molecules of biopharmaceutical interest such as amino acids, heterocyclic bases, etc (Behrendt et al 1976; Costantino 1979; Maya and Danis 1980; Szirtes et al 1988) within the layers of crystalline $\alpha$ zirconium phosphate $(\alpha \mathrm{ZrP})$.

Three oxygens of each phosphate group are bonded to three different zirconium, atoms while the fourth oxygen bears the exchangeable proton that can be easily replaced by other cations. Compounds in which the $\equiv \mathbf{P}-\mathbf{R}$ or $\equiv \mathrm{P}-\mathrm{OR}$ groups $(\mathrm{R}=$ organic alkyl/aryl radicals such as $\mathrm{H}_{2} \mathrm{O}_{3} \mathrm{P} \cdot \mathrm{CH}_{2} \mathrm{OH} / \mathrm{H}_{2} \mathrm{O}_{3} \mathrm{P} \cdot \mathrm{C}_{6} \mathrm{H}_{5}$ ) are reported (Alberti et al 1985: Alberti and Costantino 1991).

Apart from the fundamental aspects, there is an increasing interest in the potential applications of inorganoorganic ion exchangers. According to the nature of $\mathbf{R}$ group, different applications in the field of chromatographic separation (Alberti et al 1989), catalysis (Alberti et al 1993a), photochemistry (Vermeulen and Thompson 1992), protonic conduction (Casciola et al 1990; Alberti et al 1993b; Alberti and Casciola 1997) and radiochemical studies (Tomita Isao 1996), are possible. Organic derivatives are used as supports in gas chromatography, thin layer chromatography and molecular sieves (Alberti et al 1993a). The loading potential of the inorganic backbone is as high as two alkyl groups per zirconium atom, which is a distinct advantage over commercial reverse phase chromatography supports. Besides, inorgano-organic materials are known to have a large selectivity for mono and multivalent cations (Costantino 1979).

Organic derivatives of layered $\alpha \mathrm{ZrP}$ can be termed as 
intercalation compounds or lamellar compounds. In case of $\gamma \mathrm{ZrP}$ however, derivatization takes place through a topotactic reaction which consists of the substitution of $\mathrm{O}_{3} \mathrm{POH}$ tetrahedra in a preformed layered phosphate by $\mathrm{O}_{3} \mathrm{PR}$ tetrahedra, whilst retaining the original layered structure (Alberti 1990; Alberti et al 1992, 1993b). Using this method, substitution of the $\mathrm{OH}$ by $\mathrm{R}$ groups (Alberti et al 1994) takes place as follows

$\mathrm{M}(\mathrm{IV})\left(\mathrm{HPO}_{4}\right)_{2}+2 \mathrm{RPO}_{3} \mathrm{H}_{2} \rightleftharpoons \mathrm{M}(\mathrm{IV})\left(\mathrm{RPO}_{3}\right)_{2}+2 \mathrm{H}_{3} \mathrm{PO}_{4}$.

In the present endeavour, an attempt has been made to synthesize an inorgano--organic ion exchanger ZWoCP by treating an inorganic ion exchanger zirconium tungstate (ZW) reported by us earlier (Kale et al 1994) with an organic moiety ortho-chlorophenol $(o \mathrm{CP})$.

ZWoCP has been characterized for elemental analysis, spectral analysis (FTIR) and thermal analysis (TGA). Ion exchange capacity (IEC) has been determined and the effect of heating on IEC studied. Distribution behaviour for several metal ions has been studied in various electrolyte concentrations, on the basis of which metal ion separations have been carried out. Binary separation of $\mathrm{Co}(\mathrm{II})$ from $\mathrm{Cu}(\mathrm{II}), \mathrm{Zn}(\mathrm{II})$ and $\mathrm{Pb}(\mathrm{II})$ has been achieved.

\section{Experimental}

\subsection{Preparation of zirconium tungstate ( $Z W)$}

$\mathrm{ZW}$ has been prepared by adding an aqueous solution of sodium tungstate to an aqueous solution of zirconium oxychloride till complete precipitation. The $\mathrm{pH}$ was adjusted to $\sim 8$ using very dilute ammonia followed by washing with conductivity water till the washings were chloride free. The precipitates were dried at $-40^{\circ} \mathrm{C}$ and sieved to the desired particle size (30-60 mesh). The sample was then converted to the hydrogen form by immersion in $1 \mathrm{M} \mathrm{HCl}$, the acid being replaced intermittently. It was then washed repeatedly with conductivity water till free of chloride ion and finally dried at $40^{\circ} \mathrm{C}$.

\subsection{Preparation of organic derivative ( $\mathrm{ZWoCP}$ )}

$\mathrm{ZWoCP}$ was prepared by heating under reflux I $\mathrm{g}$ of the acid treated $\mathrm{ZW}$ with $20 \mathrm{ml}$ of pure distilled $o$-chlorophenol. The excess of the organic reagent was decanted. This was followed by washing the sample with alcohol and finally drying it at $\sim 40^{\circ} \mathrm{C}$. The amount of $o \mathrm{CP}$ anchored onto $\mathrm{ZW}$ was estimated as the difference between the initial and final concentration by the bromination method (Vogel 1989).

\subsection{Characterization}

Zirconium and tungsten in ZW and ZWoCP were estimated gravimetrically as zirconium oxide by cupferron method (Elving and Olson 1955) and as barium tungstate (Vogel 1978), respectively. Carbon and hydrogen in ZWoCP were determined using a Coleman analyser model 33. Thermograms (TGA) were recorded on a Shimadzu DT-30 thermal analyser at a heating rate of $10^{\circ} \mathrm{C} \mathrm{min}{ }^{-1}$. FTIR spectra were recorded on a Perkin Elmer model 1720X equipped with Epson Hi 80 printer/plotter. Sample preparation was done using $\mathrm{KBr}$ as reference with $1 \%$ sample concentration.

Chemical stability of ZWoCP was checked in several mineral acids such as $\mathrm{HCl}, \mathrm{HNO}_{3}$ and $\mathrm{H}_{2} \mathrm{SO}_{4}$; bases such as $\mathrm{NaOH}$ and $\mathrm{KOH}$; and organic solvents such as alcohol, acetone and diethyl ether. $500 \mathrm{mg}$ each of ZWoCP was taken in $50 \mathrm{ml}$ of different solvents and kept for $24 \mathrm{~h}$ and the changes in colour, nature and weight of the sample were noted.

The ion exchange capacity (IEC) was determined by the column method (Nabi and Rao 1981) and the effect of heating on IEC was studied by heating the exchangers at various temperatures in the range $100^{\circ}-500^{\circ} \mathrm{C}$ for $2 \mathrm{~h}$ each in a muffle furnace.

\subsection{Distribution studies}

Ion exchange behaviour for several metal ions such as transition metals $\left(\mathrm{Zn}^{2+}, \mathrm{Cu}^{2+}, \mathrm{Ni}^{2+}, \mathrm{Mn}^{2+}, \mathrm{Co}^{2+}\right)$; heavy metals $\left(\mathrm{Pb}^{2+}, \mathrm{Bi}^{3+}, \mathrm{Hg}^{2+}\right)$ and rare earths $\left(\mathrm{La}^{3+}, \mathrm{Ce}^{4+}\right.$, $\left.\mathrm{Th}^{4+}\right)$ was studied and their distribution coefficient $\left(K_{\mathrm{d}}\right)$ determined. $K_{\mathrm{d}}$ is defined as

$$
K_{\mathrm{d}}=\frac{I-F}{F} \times \frac{V}{W}\left(\mathrm{ml} \mathrm{g}^{-1}\right),
$$

where, $I$ is the initial amount of the metal ion in solution, $F$ the final amount of the metal ion in solution, $V$ the volume of the metal ion solution taken for analysis (ml) and $W$ the weight of the exchanger taken for analysis (g).

The ion exchanger $(0.1 \mathrm{~g})$ was equilibrated with a $0.001 \mathrm{M}(20 \mathrm{ml})$ solution of the metal ion at room temperature for $24 \mathrm{~h}$ with intermittent shaking. The uptake of the metal ion was determined as a difference in the initial and the residual concentrations of the metal ion using EDTA as a titrant. Distribution studies were also carried out for all the above mentioned metal ions in different electrolyte media such as $0.001 \mathrm{M}, 0.1 \mathrm{M}, 0.4 \mathrm{M}$ $\mathrm{HNO}_{3}$ and $0.05 \mathrm{M}, 0.5 \mathrm{M}$ and $1 \mathrm{M} \mathrm{NH} \mathrm{NO}_{3}$ solutions.

\subsection{Metal ion separations}

For binary separations, $5 \mathrm{~g}$ of the ion exchanger in $\mathrm{H}^{+}$ form was taken in a glass column $(30 \mathrm{~cm} \times 1.1 \mathrm{~cm}$ dia). The column was washed thoroughly with deionized water and the mixture to be separated was loaded on to it maintaining a flow rate of $0.5 \mathrm{ml} \mathrm{min}^{-1}$. In all the sepa- 
rations, the cation concentration was maintained at $0.001 \mathrm{M}$ concentration and $5 \mathrm{ml}$ of each metal ion solution was taken. The separation of $\mathrm{Co}$ (II) from $\mathrm{Cu}$ (II), $\mathrm{Zn}$ (II) and $\mathrm{Pb}$ (II) was achieved by passing a suitable eluant and the metal ion in the effluant was determined quantitatively by EDTA titrations.

\section{Results and discussion}

Chemical analysis indicates the composition of $\mathrm{Zr}: \mathrm{W}$ to be $1: 2$. Based on this and the TGA data, the proposed formula for $\mathrm{ZW}$ is $\mathrm{ZrO}_{2} \cdot 2 \mathrm{WO}_{4} \cdot 9 \mathrm{H}_{2} \mathrm{O}$. The number of water molecules was determined using Alberti's formula (Alberti and Torracca 1972). In case of ZWoCP, elemental analysis indicates, $\% \mathrm{C}=4.908 ; \% \mathrm{H}=2.488$ (instrumental elemental analysis) and $\% \mathrm{C}=5.76 ; \% \mathrm{H}=2.12$ (bromination method).

$\mathrm{ZWoCP}$, though stable in $\mathrm{HCl}(11.3 \mathrm{~N})$ and $\mathrm{H}_{2} \mathrm{SO}_{4}$ $(36 \mathrm{~N})$, was stable in $\mathrm{HNO}_{3}$ only up to $0.5 \mathrm{~N}$ concentration. ZWoCP was found to be stable in bases such as $\mathrm{NaOH}$ and $\mathrm{KOH}$ up to $2 \mathrm{M}$ concentration, as evidenced by no change in colour, form or weight of the samples used. ZWoCP was also found stable in ethanol, acetone and diethyl ether.

FTIR spectra of ZW (figure la) shows broad bands in the $\sim 3400 \mathrm{~cm}^{-1}$ region characteristic of asymmetric and symmetric hydroxo-OH and aquo-OH stretching frequency. A sharp medium band at $1620 \mathrm{~cm}^{-1}$ is attributed to $(\mathrm{H}-\mathrm{O}-\mathrm{H})$ bending frequency. The FTIR spectrum of $\mathrm{ZWoCP}$ (figure $1 \mathrm{~b}$ ) shows additional bands in the -1580 $1460 \mathrm{~cm}^{-1}$ region characteristic of the $\mathrm{C}=\mathrm{C}$ skeletal inplane vibrations. Bands in the $-1390-1330 \mathrm{~cm}^{-1}$ region are due to the interactions of the $-\mathrm{OH}$ bending and $\mathrm{C}-\mathrm{H}$ stretching frequencies. Weak bands in the $\sim 1410$ $1310 \mathrm{~cm}^{-1}$ region and at $1200 \mathrm{~cm}^{-1}$ are due to $\mathrm{C}-\mathrm{O}$ stretching frequency.

The TGA of $\mathrm{ZW}$ indicates presence of hydrated water which is lost very slowly between $100^{\circ}-180^{\circ} \mathrm{C}$. TGA of $\mathrm{ZWoCP}$ indicates a weight loss at $\sim 61^{\circ} \mathrm{C}$ due to traces of solvent used for washing the exchanger after refluxing. There is a gradual decrease in weight up to $500^{\circ} \mathrm{C}$ indicative of the dissociation and decomposition of the organic moiety from the support and the condensation of the structural hydroxyl groups.

The IEC of $\mathrm{ZW}$ at room temperature is $0.58 \mathrm{meq} \mathrm{g}^{-1}$ whereas that of $\mathrm{ZWoCP}$ is $0.65 \mathrm{meq}^{-1}$. A higher value of IEC in case of ZWoCP is due to the additional $\mathrm{H}^{+}$ sites of the ionogenic - $\mathrm{OH}$ groups in the benzene ring of the $o$-chlorophenol, besides the electron withdrawing phenyl ring also makes the phenolic $(-\mathrm{OH})$ proton more labile.
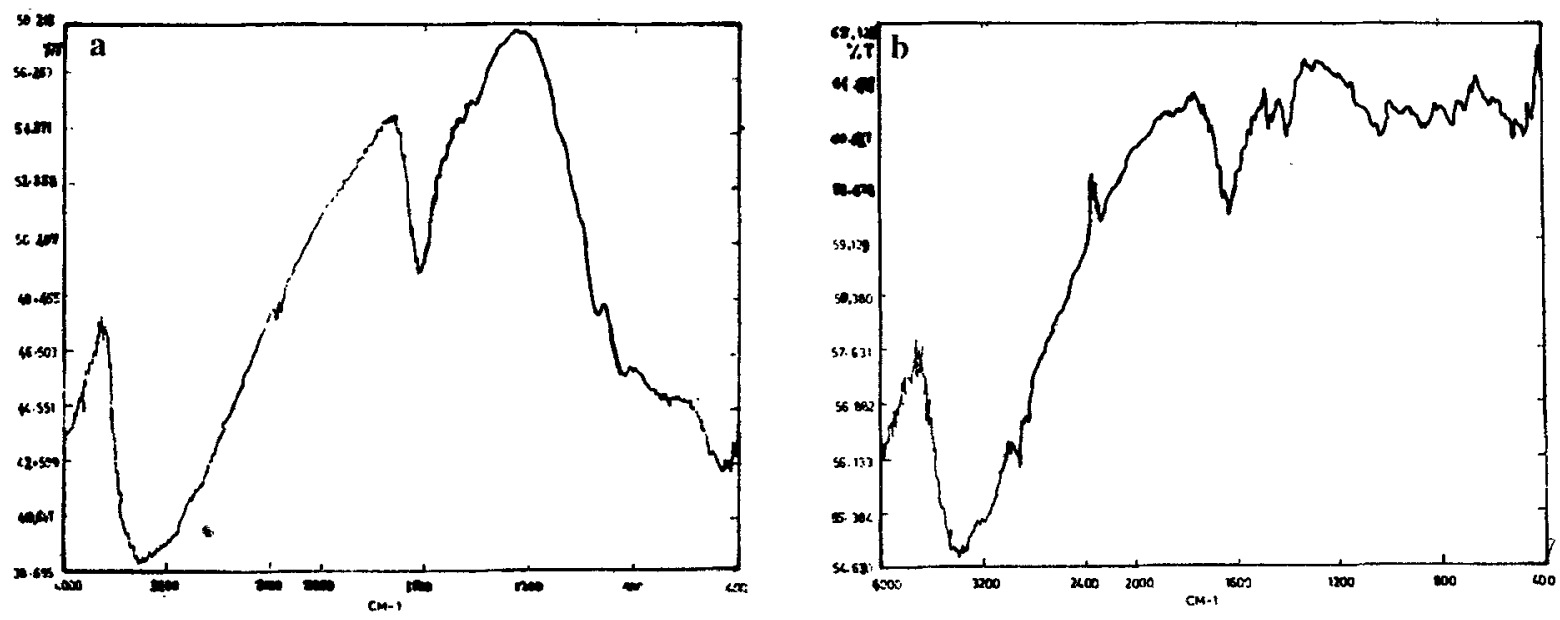

Figure 1. FTIR spectrum of a. ZW and b. ZWoCP.

Table 1. Effect of heating on IEC of $\mathrm{ZW}$ and $\mathrm{ZWoCP}$.

\begin{tabular}{|c|c|c|c|c|}
\hline \multirow{2}{*}{$\begin{array}{l}\text { Temperature } \\
\left({ }^{\circ} \mathrm{C}\right)\end{array}$} & \multicolumn{2}{|c|}{ Colour change } & \multicolumn{2}{|c|}{ Ion exchange capacity $\left(\mathrm{meq} \cdot \mathrm{g}^{-1}\right)$} \\
\hline & $\mathrm{ZW}$ & ZWoCP & ZW & ZWoCP \\
\hline RT & White & Yellowish brown & 0.58 & 0.64 \\
\hline 100 & Light brown & Brown & 0.40 & $0 \cdot 37$ \\
\hline 200 & Light brown & Black & 0.36 & $0 \cdot 21$ \\
\hline 300 & White & Black & 0.26 & 0.48 \\
\hline 400 & White & Dark brown & 0.24 & 0.41 \\
\hline 500 & White & White & 0.22 & $0 \cdot 30$ \\
\hline
\end{tabular}


Table 2. Effect of the electrolyte concentration on the $K_{d}$ values of metal ions for ZWoCP.

\begin{tabular}{lccccccc}
\hline Metal ion & D.W. & $\begin{array}{c}0.01 \mathrm{M} \\
\mathrm{HNO}_{3}\end{array}$ & $\begin{array}{c}0.1 \mathrm{M} \\
\mathrm{HNO}_{3}\end{array}$ & $\begin{array}{c}0.4 \mathrm{M} \\
\mathrm{HNO}_{3}\end{array}$ & $\begin{array}{c}0.05 \mathrm{M} \\
\mathrm{NH}_{4} \mathrm{NO}_{3}\end{array}$ & $\begin{array}{c}0.5 \mathrm{M} \\
\mathrm{NH}_{4} \mathrm{NO}_{3}\end{array}$ & $\begin{array}{c}1 \mathrm{M} \\
\mathrm{NH}_{4} \mathrm{NO}_{3}\end{array}$ \\
\hline $\mathrm{Cu}^{2+}$ & 83.89 & 6.78 & 6.78 & $\mathrm{NS}$ & 83.90 & 83.90 & 83.90 \\
$\mathrm{Zn}^{2+}$ & 67.20 & $\mathrm{NS}$ & $\mathrm{NS}$ & $\mathrm{NS}$ & 7.29 & $\mathrm{NS}$ & $\mathrm{NS}$ \\
$\mathrm{Co}^{2+}$ & 23.65 & $\mathrm{NS}$ & $\mathrm{NS}$ & $\mathrm{NS}$ & 10.22 & 6.78 & 5.04 \\
$\mathrm{Mn}^{2+}$ & 78.92 & $\mathrm{NS}$ & $\mathrm{NS}$ & $\mathrm{NS}$ & 7.32 & 2.04 & $\mathrm{NS}$ \\
$\mathrm{Ni}^{2+}$ & 16.88 & $\mathrm{NS}$ & $\mathrm{NS}$ & $\mathrm{NS}$ & 15.37 & 13.63 & $\mathrm{NS}$ \\
$\mathrm{Pb}^{2+}$ & 99.21 & 8.55 & 6.78 & $\mathrm{NS}$ & 87.05 & 90.82 & 95.88 \\
$\mathrm{Hg}^{2+}$ & 14.36 & 11.94 & 6.78 & $\mathrm{NS}$ & 13.76 & 17.84 & 20.81 \\
$\mathrm{Bi}^{3+}$ & 1151.70 & 240.43 & 41.46 & $\mathrm{NS}$ & 64.00 & 53.84 & 27.59 \\
$\mathrm{La}^{3+}$ & $\mathrm{NS}$ & $\mathrm{NS}$ & $\mathrm{NS}$ & $\mathrm{NS}$ & $\mathrm{NS}$ & $\mathrm{NS}$ & $\mathrm{NS}$ \\
$\mathrm{Ce}^{4+}$ & $\mathrm{NS}$ & $\mathrm{NS}$ & $\mathrm{NS}$ & $\mathrm{NS}$ & $\mathrm{NS}$ & $\mathrm{NS}$ & $\mathrm{NS}$ \\
$\mathrm{Th}^{4+}$ & 67.20 & 65.15 & 60.23 & 53.30 & 45.41 & 45.00 & 40.00 \\
\hline
\end{tabular}

*NS, No sorption

Table 3. Metal ion separation for $\mathrm{ZWoCP}$.

\begin{tabular}{llccc}
\hline $\begin{array}{l}\text { Separation } \\
\text { achieved }\end{array}$ & \multicolumn{1}{c}{ Eluants } & $\begin{array}{c}\text { Amount loaded } \\
(\mathrm{mg})\end{array}$ & $\begin{array}{c}\text { Amount eluted } \\
(\mathrm{mg})\end{array}$ & \% Efficiency \\
\hline & & & & \\
$\mathrm{Co}(\mathrm{II})-\mathrm{Cu}(\mathrm{II})$ & $0.05 \mathrm{M} \mathrm{NH}_{4} \mathrm{NO}_{3}(\mathrm{Co})$ & 0.2829 & 0.2593 & 91.66 \\
& $0.01 \mathrm{M} \mathrm{HCl}^{(\mathrm{Cu})}$ & 0.3433 & 0.1907 & 55.00 \\
$\mathrm{Co}(\mathrm{II})-\mathrm{Zn}(\mathrm{II})$ & $0.01 \mathrm{M} \mathrm{HNO}_{3}(\mathrm{Co})$ & 0.2829 & 0.2574 & 91.00 \\
& $0.05 \mathrm{M} \mathrm{NH}_{4} \mathrm{NO}_{3}(\mathrm{Zn})$ & 1.6077 & 1.3714 & 85.30 \\
$\mathrm{Co}(\mathrm{II})-\mathrm{Pb}(\mathrm{II})$ & $0.05 \mathrm{M} \mathrm{NH}_{4} \mathrm{NO}_{3}(\mathrm{Co})$ & 0.2829 & 0.2652 & 93.00 \\
& $0.01 \mathrm{M} \mathrm{HNO}_{3}(\mathrm{~Pb})$ & 1.0774 & 1.0567 & 98.00 \\
\hline
\end{tabular}

The results of the effect of heating on IEC are summarized in table 1. For $\mathrm{ZW}$, the IEC decreases on heating. This is due to the condensation of the structural hydroxyl groups bearing the exchangeable protons, at higher temperatures. However in case of $\mathrm{ZWoCP}$, the IEC decreases up to $200^{\circ} \mathrm{C}$ and then increases for the sample heated at $300^{\circ} \mathrm{C}$. Again for the samples heated at $400^{\circ}$ and $500^{\circ} \mathrm{C}$, the IEC decreases. This may be due to the fact that on heating in the range $200^{\circ}-300^{\circ} \mathrm{C}$, the organic moiety decomposes leading to the formation of active carbon as evidenced by the change in colour of the sample to black. This is responsible for an increase in the IEC and is later lost as $\mathrm{CO}_{2}$ as the heating temperature increases. This fact is also evident from the IR spectra of heated samples of ZW and ZWoCP.

The distribution coefficient $\left(K_{\mathrm{d}}\right)$ calculated for the metal ions in different electrolyte concentrations for ZWoCP are summarized in table 2 . On the basis of the selective affinity for particular metal ions in the presence of electrolytes, the metal ion $\mathrm{Co}$ (II) has been separated from $\mathrm{Cu}(\mathrm{II}), \mathrm{Zn}(\mathrm{II})$, and $\mathrm{Pb}(\mathrm{II}) . \mathrm{Co}(\mathrm{II})$ has been eluted using $0.05 \mathrm{M} \mathrm{NH}_{4} \mathrm{NO}_{3}$ in all the separations except for $\mathrm{Co}(\mathrm{II})-\mathrm{Zn}$ (II) separation, where it is eluted using $0.01 \mathrm{M}$ $\mathrm{HNO}_{3} . \mathrm{Cu}(\mathrm{II}), \mathrm{Zn}(\mathrm{II})$ and $\mathrm{Pb}(\mathrm{II})$ were eluted using $0 \cdot 01$ $\mathrm{M} \mathrm{HCl}, 0.01$ and $0.4 \mathrm{M} \mathrm{HNO}_{3}$ solutions, respectively. The results of the separation study are summarized in table 3 .

\section{Conclusion}

ZWoCP exhibits good ion exchange capacity and is stable up to a fairly high temperature, besides exhibiting stability in different acidic, basic and organic media. Its selectivity for particular metal ions enables it to act as an efficient ion exchanger for the separation of $\mathrm{Co}$ (II) from $\mathrm{Cu}(\mathrm{II}), \mathrm{Zn}(\mathrm{II})$ and $\mathrm{Pb}(\mathrm{II})$ with $\sim 93 \%$ efficiency. The DTMA ZWoCP thus exhibits the characteristics of a promising ion exchanger.

\section{Acknowledgements}

Thanks are due to the Head, Department of Applied Chemistry for providing the necessary laboratory facilities. One of the authors (BP) is also thankful to the M.S. University of Baroda, Vadodara for providing a fellowship.

\section{References}

Alberti G 1990 Pillared layered structures: Current trends and applications (ed.) I V Mitchell (London: Elsevier) p. 119

Alberti G and Torracca E 1972 J. Inorg. Nucl. Chem. 342643

Alberti G and Costantino U 1982 Intercalation chemistry (New York: Academic Press Inc.) p. 147

Alberti $\mathbf{G}$ and Costantino $\mathbf{U} 1991$ Intercalation of zirconium phosphates and phosphonates, in Inclusion compounds (eds) 
J L Atwood, J E D Davies and D D McNicol (London: Oxford University Press) 5 p. 136

Alberti G and Casciola M 1997 Solid State lonics 97177

Alberti G, Costantino U, Allulli S and Tomassini N $1978 \mathrm{~J}$. Inorg. Nucl. Chem. 401113

Alberti G, Costantino U and Giovagnotti Luciani M L $1980 \mathrm{~J}$. Inorg. Nucl. Chem. 41643

Alberti G, Costantino U, Komyei J and Giovagnotti Luciani $M$ L 1982 Chim. Ind. (Milan) 64115

Alberti G, Costantino U, Komyei J and Giovagnotti Luciani M L 1985 React. Polym. 51

Alberti G, Costantino U, Marmottini F and Perego G 1989 Gaz. Chim. Ital. 119191

Alberti G, Costantino L, Vivani R and Biswas R K 1992 React. Polym. 17245

Alberti G, Costantino U, Vivani R and Zappelli P 1993a Angew. Chem. Int. Ed. Engl. 321357

Alberti G, Vivani R, Biswas R K and Murcia Mascaros S 1993 b React. Polym. 191

Alberti G, Marmottini F, Murcia Mascaros S and Vivani R 1994 Angew. Chem. Int. Ed. Engl. 331594

Behrendt D, Beneke K and Lagaly G 1976 Angew. Chem. Int. Ed. Engl. 15544
Casciola M, Chieli S and Costantino U 1990 Proc. of the fifth int conf. on solid state protonic conductors $B_{4}$ (Assissi, Italy: University of Perugia)

Clearfield A and Stynes J A 1964 J. Inorg. Nucl. Chem. 26 117

Costantino U 1979 J. Chem. Soc. Dalton Trans. 402

Costantino U, Massucci M A, La Ginestra A, Tarola A M and Zampa L 1986 J. Incl. Phenom. 4147

Elving Ph J and Olson E C 1955 Anal. Chem. 271817

Kale A, Pandit B, Beena B and Chudasama U 1994 J.M.S.U. XLI 25

Kornyei J 1982 II Int. symp. on clatharate compounds and molecular inclusion phenomenon, Parma, Italy p. 8

Maya L and Danis P O $1980 \mathrm{~J}$. Chromatogr. 190145

Nabi S A and Rao R K 1981 J. Indian Chem. Soc. 111030

Szirtes L, Kornyei J and Poko Z 1988 React. Polym. 7185

Tomita Isao 1996 Nippon Ion Kokan Gakkaishi (Jpn) 7174

Vermeulen L A and Thompson M E 1992 Nature 358656

Vogel A I 1978 Textbook of quantitative inorganic analysis (London: Longman Green) IV Ed.

Vogel A I 1989 Elementary practical organic chemistry, Part III, Quantitative chemistry (London: ELBS and Longman Group Ltd.) 